\title{
Erratum to: A System Maturity Model for Supply Chain Management
}

\author{
Shigeki Umeda ${ }^{(\bowtie)}$ \\ Musashi University, 1-26 Toyotama-kami, Nerima, Tokyo 176-8534, Japan \\ shigeki@cc.musashi.ac.jp
}

\section{Erratum to:}

\section{Chapter "A System Maturity Model for Supply Chain} Management" in: H. Lödding et al. (Eds.): Advances in Production Management Systems (Part II), IFIP AICT 514, https://doi.org/10.1007/978-3-319-66926-7_1

Due to a mistake during the uploading process the originally published article proposed a methodology for a performance sensitivity analysis. As this is not in alignment with the intended content of the paper, the following changes have been made in the updated version:

- Exclusion of the chapter Scenarios and Models

- Exclusion of the chapter System Sensitivity Analysis by Using Simulations

- Inclusion of the chapter Supply Chain Maturity Model: SCMM

- Inclusion of the chapter Supply Chain Maturity Model with business management problems

- Inclusion of the chapter Supply chain management problems and investment problems on information technologies

- Alignment of the introduction and the conclusion to the new content

The updated online version of this chapter can be found at https://doi.org/10.1007/978-3-319-66926-7_1 